\title{
Seven-year survival after transapical transcatheter aortic valve implantation for intermediate and high surgical risk or inoperable patients
}

\author{
Michal Hulman, Martin Beňa, Ivo Gasparovič, Vladan Hudec, \\ Branislav Bezák, Panagiotis Artemiou
}

Clinic of Cardiac Surgery, Medical Faculty of the Comenius University, National Institute of Cardiovascular Diseases, Bratislava, Slovakia

ARTICLE INFO

Article history:

Submitted: 22. 7. 2020

Revised: 22. 9. 2020

Accepted: 22. 9. 2020

Available online: 5. 2. 2021
Klíčová slova:
Transapikální prístup
Keywords:
Transkatétrová implantace aortální chlopně
Transapical access
Transcatheter aortic valve implantation

Transcatheter aortic valve implantation (TAVI) was developed as an alternative treatment modality for patients with severe symptomatic aortic valve stenosis, for whom the operative risk for surgical aortic valve replacement (SAVR) is considered too high or prohibitive. TAVI is now considered to be equivalent or superior to SAVR in high risk or inoperable patients. ${ }^{1}$ Long-term data concerning the survival of these patients beyond the 5-year horizon are still limited. In this short communication, we present the 7-year survival of intermediate and high surgical risk or inoperable patients with symptomatic severe aortic valve stenosis that underwent transapical TAVI (TA-TAVI) in our institute, irrespective of the cause of death (cardiac and non-cardiac causes).

Between April 2012 and December 2019, 169 patients (79 male and 60 female patients) with symptomatic severe aortic valve stenosis underwent TA-TAVI with the balloon expandable SAPIEN XT and SAPIEN S3 (Edwards Lifesciences, Irvine, CA, USA) valves. All the patients were intermediate or high-risk for conventional surgery or inoperable and had additional predisposing risk factors like porcelain aorta or redo-surgery. The patients were indicated for TA-TAVI by the heart team because the transfemoral access was not possible due to size, tortuosity, or calcification of the femoral vessels. The ratio of transapical to transfemoral implantations was $1: 3$. Patients' informed consent was obtained to present this communication. The mortality data were taken from the

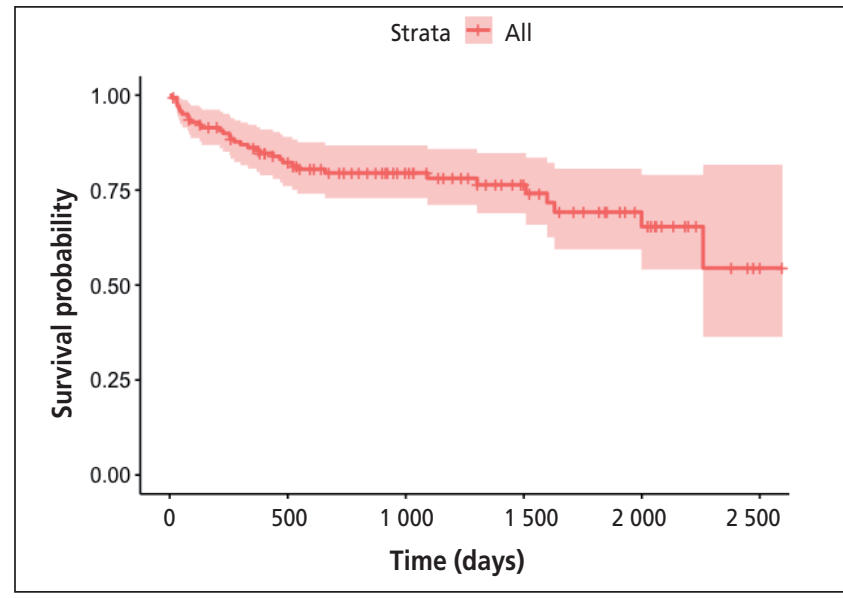

Fig. 1 - Kaplan-Meier survival curve.

National Center of Health Information. The mean age and EUROscore II of the patients were 76.98 \pm 7.06 years and $5.9 \pm 5.14$ respectively. The 5-year and 7-year survival of the patients were $69.2 \%$ and $54.5 \%$ respectively (Fig. 1 - Kaplan-Meier survival curve).

Survival rate beyond the 5-year horizon was reported in five recently published experiences on high-risk populations ranging from $9.6 \%$ to $29.8 \% .^{2-7}$

Follow-up data of up to five years survival after TAVI are available from different registries and from the Place-

Address: MUDr. Panagiotis Artemiou, PhD., Clinic of Cardiac Surgery, Medical Faculty of the Comenius University, National Institute of Cardiovascular Diseases, Pod Krásnou hôrkou 1, 83101 Bratislava, Slovakia, e-mail: panayiotisartemiou@yahoo.com

(C) 2021, ČKS.

DOI: $10.33678 /$ cor.2020.085 
ment of Aortic Transcatheter Valves (PARTNER) trial ${ }^{1,8-9}$ ranging from $39.2 \%$ to $44.7 \%$.

Our results are consistent with the above previous publications, and the survival rate observed can be explained by the advanced age of the patients and the high surgical risk. The better 5-year and 7-year survival that is reported in our communication can be explained by the lower risk profile of our cohort (less EUROscore value/intermediate risk and relatively young patients).

Moreover the type of the TAVI device and the access route did not affect the survival outcome. ${ }^{7}$

Our findings, as also findings from other previous published reports show acceptable long-term results, and TAVI as an alternative to surgery for intermediate-risk and high-risk patients with better results. TAVI is the default choice for treating aortic valve stenosis in intermediate or high risk and inoperable patients.

\section{Conflict of interest}

The authors declare no conflict of interest.

\section{Funding}

The authors declare no funding.

\section{References}

1. Mack MJ, Leon MB, Smith CR, et al. 5-year outcomes of transcatheter aortic valve replacement or surgical aortic valve replacement for high surgical risk patients with aortic stenosis (PARTNER 1): a randomized controlled trial. Lancet 2015;385:2477-2484.
2. Testa L, Latib A, Brambilla N, et al. Long-term clinical outcome and performance of transcatheter aortic valve replacement with a self-expandable bioprosthesis. Eur Heart J 2020;41:1876-1886.

3. Eitchaninoff H, Durant E, Avinee G, et al. Assessment of structural valve deterioration of transcatheter aortic bioprosthetic balloon-expandable valves using the new European consensus definition. Eurolntervention 2018;14:e264-e271.

4. Barbanti M, Costa G, Zappulla P, et al. Incidence of long-term structural valve dysfunction and bioprosthetic valve failure after transcatheter aortic valve replacement. J Am Heart Assoc 2018;7:e008440.

5. Panico RA, Giannini C, De Carlo M, et al. Long-term results and durability of the CoreValve transcatheter aortic bioprosthesis: outcomes beyond five years. Eurolntervention 2019;14:16391647.

6. Holy EW, Kebernik J, Abdelghani M, et al. Long-term durability and haemodynamic performance of a selfexpanding transcatheter heart valve beyond five years after implantation: a prospective observational study applying the standardized definitions of structural deterioration and valve failure. Eurolntervention 2018;14:e390-e396.

7. Deutsch MA, Erlebach M, Burri M, et al. Beyond the five-year horizon: long-term outcome of high-risk and inoperable patients undergoing TAVR with first-generation devices Eurolntervention 2018;14:41-49.

8. Didier R, Eitchaninoff H, Donzeau-Gouge $P$, et al. Five-year clinical outcome and durability after transcatheter aortic valve replacement in high-risk patients FRANCE-2 registry. Circulation 2018;138:2597-2607.

9. Gleason TG, Reardon MJ, Popma JJ, et al. CoreValve U.S Pivotal High Risk Trial Clinical Investigators. 5-year outcomes of self-expanding transcatheter versus surgical aortic valve replacement in high-risk patients. J Am Coll Cardiol 2018;72:2687-2696. 